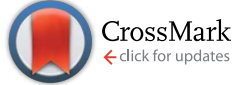

Cite this: RSC Adv., 2015, 5, 29741

Received 18th December 2014 Accepted 24th February 2015

DOI: $10.1039 / c 4 r a 16643 d$

www.rsc.org/advances

\section{Dielectric relaxation and electro-optic response in nano-ceria dispersed ferroelectric liquid crystal nanocomposites: effect of structural deformation and lattice straining}

\begin{abstract}
Puja Goel*a and Manju Arorab
The current investigations deal with the effect of concentration of $\mathrm{CeO}_{2}$ nanoparticles (NPs) on physical properties of ferroelectric liquid crystal. Infrared transmission spectroscopy has been used to reveal the mechanism behind significant changes in dielectric behavior and electro-optic parameters of nanocomposites, for the first time, in correlation with structural deformation of functional group present in FLC and lattice straining induced by the NPs. The temperature and frequency dependence of dielectric permittivity exhibits a gradual increase in the dielectric constant with the addition of $\mathrm{CeO}_{2} \mathrm{NPs}$. An increase in the saturated spontaneous polarization $\left(P_{\mathrm{s}}\right)$ and switching at a lower bias was also observed in these nanocomposites. IR transmission peaks pertaining to the $\nu \mathrm{C}=\mathrm{O}$ and $\nu \mathrm{C}-\mathrm{O}$ stretching modes of FLC's ester (RCOOR') functional group showed a shift in the peak positions and a new weak intensity $\mathrm{C}=\mathrm{O}$ bonded chiral group vibrational mode at $1718 \mathrm{~cm}^{-1}$ was observed after ceria dispersion. These variations are attributed to the coordinated bond formation between planar polar ester $\mathrm{C}=\mathrm{O}$ group and $\mathrm{Ce}^{3+}$ ion through the lone pairs of oxygen and the stress induced by $\mathrm{CeO}_{2} \mathrm{NPs}$ present in the interstitial sites of FLC's polar component. These structural distortions facilitate the easy polarizability of FLC molecules with an enhancement in the dielectric constant and $P_{\mathrm{s}}$ values. In addition, the loss profile demonstrates an increase in the frequency and magnitude of ion linked relaxation and Goldstone mode after ceria dispersion, whereas losses on their lower frequency side decreases.
\end{abstract}

\section{Introduction}

Ferroelectric liquid crystals (FLCs) have gained considerable research momentum from the past few decades because they render potential applications in the field of flat panel displays, luminescent liquid crystal displays, spatial light modulators, optical storage, optical switching and electro-optic memory devices. ${ }^{1-7}$ The incorporation of nanomaterials in FLCs has opened up new avenues for use in various novel multidisciplinary applications with a marked enhancement in performance efficiency.

Earlier investigations have revealed that the interaction of NPs dispersed in FLCs nanocolloids plays a key role in determining the dielectric, optical and switching behaviors that are requisite for the use of FLCs in device applications. In addition to this, several new observations in dielectric and static memory effect and anomalous high and low frequency dielectric relaxations have been correlated with the type and size of the doped

${ }^{a}$ Division of Agricultural Chemicals, Indian Agricultural Research Institute, New Delhi 110012, India.E-mail: pujagoel@gmail.com

${ }^{b}$ CSIR - National Physical Laboratory, Dr. K.S. Krishnan Marg, New Delhi 110012, India
NPs. Room temperature dielectric memory effect was reported for cobalt ferrite NPs $(\sim 9 \mathrm{~nm})$ dispersed FLCs nanocomposites, which becomes more pronounced as the temperature raised to smectic $\mathrm{C}^{*}\left(\mathrm{SmC}^{*}\right)$ to smectic A $(\mathrm{SmA})$ phase transition. ${ }^{8}$ However, in a mixture of FLC and Ni NPs, ${ }^{9}$ a high frequency relaxation mode in conjunction with the collective dielectric mode is induced, which persists even in the SmA phase of the material. In addition to this, a temperature dependent response time in FLC-Ni mixtures showed a significant improvement owing to the combined effect of decreased rotational viscosity and slightly increased spontaneous polarisation in presence of Ni NPs. The dispersion of dye molecules in FLC has been found to change many physical properties of FLCs, which depend upon the dye molecular structure and its concentration. ${ }^{10}$ In a fullerene and FLC composite, illumination by the focused light of a halogen lamp alters the complex permittivity in a low frequency range due to the formation of additional electron exchange channels between ions and electrodes through fullerene. ${ }^{11}$ The doping of different size and concentration of CdS nanorods in FLC and antiferroelectric liquid crystals (AFLC) have increased the spontaneous polarization, response time and photoluminescence properties. ${ }^{12,13}$ Among the metal oxide/rare earth oxide nanomaterials in FLCs studies, nano- 
ceria $\left(\mathrm{CeO}_{2}\right)$ has imparted its optical properties to the host FLC. ${ }^{14}$ Moreover, $\mathrm{Al}_{2} \mathrm{O}_{3}$ NPs doping reduces ionic impurities effect in FLCs through their novel adsorption capability. ${ }^{15}$

Nano-ceria has drawn a great deal of attention owing to its high chemical stability, good dielectric strength, electronic tunability and optical properties. $\mathrm{CeO}_{2}$ is a wide energy band gap semiconductor (e.g. $5.5 \mathrm{eV})$, which crystallizes in a fluorite crystal structure with the space group Fm3m consisting of a facecentred cubic (f.c.c.) unit cell. Each cerium cation is coordinated by six nearest-neighbouring oxygen anions to form $\mathrm{CeO}_{6}$ octahedra, whereas each oxygen anion is shared by four nearestneighbouring cerium cations. ${ }^{16}$ Cerium (Ce) exists in the $\mathrm{Ce}^{3+}$ and $\mathrm{Ce}^{4+}$ valence states. These oxidation states can auto regenerate and are switchable due to a nearly similar very low potential energy barrier to electron density distribution between $4 \mathrm{f}$ and $5 \mathrm{~d}$ electronic states. The regeneration of $\mathrm{Ce}^{3+}$ ionic state at the surface of $\mathrm{CeO}_{2}$ nanoparticles has been believed to be the origin of its core catalytic property. ${ }^{17,18}$ In present study, we are mainly focusing on the interaction of nanosized ceria particles with FLC (KCFLC 10s) in terms of the role of functional groups and chiral centre present in FLC, which is responsible for the resulting dielectric relaxation and electro-optic parameters in composite formation with varied ceria concentration. In this context, infrared (IR) spectroscopy has been used to draw information about the molecular conformation in FLC, type of bonding in $\mathrm{CeO}_{2}$ NPs with FLC and a shift in peak positions with a gain or loss in intensity. The variation in dielectric relaxation and spontaneous polarization has been correlated with the deformation induced by $\mathrm{CeO}_{2} \mathrm{NPs}$ in ester functional group present adjacent to FLC chiral centre and the presence of an electronegative fluoride ion in biphenyl group.

\section{Experimental}

All the dielectric and electro-optic studies on FLC and nanoceria dispersed composites were performed on the electrooptic cells of thickness $4 \mu \mathrm{m}$, which were fabricated using the photolithography technique. The method of sample preparation has already been described in our previous report. ${ }^{\mathbf{1 4}}$ For the fabrication of sample cells, glass plates with conducting $\left(=\sim 30 \Omega \mathrm{cm}^{-2}\right)$ ITO coating were used. The electrodes of $4.5 \mathrm{~mm}$ $\times 4.5 \mathrm{~mm}$ dimension were etched on these glass substrates after photoresist applications followed by soft baking, mask alignment and UV exposure. Furthermore, these patterned glass plates were spin coated with a nylon polymer and baked at $180{ }^{\circ} \mathrm{C}$ for 20 minutes in order to achieve homogeneous alignment of FLC molecules. For the fabrication of nanocomposites, a suspension of ceria NPs (Sigma Aldrich) was prepared by mixing $1 \mathrm{~g}$ of $\mathrm{CeO}_{2}$ NPs in $100 \mathrm{ml}$ of Millipore water, followed by $1 \mathrm{~h}$ of ultrasonication. The selective amounts of this suspension (i.e. 1, 3 and $5 \mu \mathrm{l}$ ) were added and mixed in a fix quantity of (3 mg) of FLC material. After this, the mixtures were heated at about $115^{\circ} \mathrm{C}$ and brought to an isotropic phase, and then mixed rigorously. This step was repeated thrice in order to ensure the complete evaporation of water and the homogenous dispersion of ceria nanoparticles into FLC matrix. Successively, pure and $\mathrm{np}-\mathrm{CeO}_{2}$ :FLC mixtures were introduced into the electro-optic cells at temperatures just above the nematic*-isotropic transition temperature $\left(\sim 112{ }^{\circ} \mathrm{C}\right)$ of the FLC material used. The phase sequence of the investigated FLC, i.e., KCFLC 10s (Kingston Chemicals Ltd.) is as follows:

$$
\mathrm{SmC}^{*} \stackrel{64.5^{\circ} \mathrm{C}}{\longrightarrow} \mathrm{SmA}^{*} \stackrel{99.5^{\circ} \mathrm{C}}{\longrightarrow} \mathrm{N}^{*} \stackrel{112{ }^{\circ} \mathrm{C}}{\longrightarrow} \text { Iso. }
$$

where $\mathrm{SmC}^{*}, \mathrm{SmA}^{*}, \mathrm{~N}^{*}$, and Iso. represent chiral smectic $\mathrm{C}$, smectic A, chiral nematic, and isotropic phases, respectively.

The effect of nanosized ceria particles on the optical textures of KCFLC has already been reported ${ }^{\mathbf{1 4}}$ and it was found that NPs are uniformly dispersed within the FLC and homogenous alignment could be retained up to $5 \mu \mathrm{l}$ of ceria NPs dispersion. In order to identify the fundamental vibration of the functional groups present in the materials and to understand the structural deformation induced in the FLC matrix on dispersing $\mathrm{CeO}_{2}$ NPs, IR spectroscopy has been used. For this purpose, room temperature FTIR transmission spectra of $\mathrm{CeO}_{2} \mathrm{NPs}$, FLC and np- $\mathrm{CeO}_{2}$ :FLC nanocomposites were recorded in the 4000$500 \mathrm{~cm}^{-1}$ region on an FTIR ALPHA T (Bruker make) spectrophotometer. In order to probe the collective and non-collective molecular processes in nanocomposites, frequency-temperature dependent dielectric measurements were performed using a fully computer controlled and automated impedance analyzer (Wayne Kerr 6540A) in the frequency range of $20 \mathrm{~Hz}$ to $1 \mathrm{MHz}$. An automatic liquid crystal tester (ALCT-P) was used for analyzing the rotational viscosity, i.e., $\eta$ and spontaneous polarisation $\left(P_{\mathrm{s}}\right)$ in FLC-NPs dispersions.

\section{Results and discussion}

Fig. 1(a) shows the transmission bands observed in the IR spectrum of $\mathrm{CeO}_{2}$ nanoparticles. The band observed at 1385 $\mathrm{cm}^{-1}$ is the characteristic vibration mode of $\mathrm{CeO}_{2}$, while the absorption corresponding to $\mathrm{Ce}-\mathrm{O}-\mathrm{C}$ vibrational stretch is positioned at $837 \mathrm{~cm}^{-1}$. The broad transmission band located at $3430 \mathrm{~cm}^{-1}$ corresponds to the $\mathrm{O}-\mathrm{H}$ stretching vibration of residual water and hydroxyl groups, whereas the absorption band at $1624 \mathrm{~cm}^{-1}$ is due to the scissor bending mode of associated water. The methylene $\left(\mathrm{CH}_{2}\right)$ of methyl group and $\mathrm{CO}_{2}$ (atmospheric carbon dioxide) gives antisymmetric and symmetric stretching modes as very weak intensity peaks at 2928 and $2856 \mathrm{~cm}^{-1}$ and weak intensity bands at 2362 and $2344 \mathrm{~cm}^{-1}$, respectively. The very weak and weak intensity bands observed at about 1167 and $1050 \mathrm{~cm}^{-1}$ are observed due to traces of nitrate ion impurity $(\mathrm{N}-\mathrm{O})$, alkyl coordinated $\mathrm{Ce}^{4+}$ $\left(\mathrm{R}-\mathrm{O}-\mathrm{Ce}^{4+}\right)$ and $\mathrm{R}-\mathrm{O}-\mathrm{Ce}^{4+} / \mathrm{Ce}^{3+}$ sample. These peaks arise from the impurity and coordination of $\mathrm{Ce}^{4+} / \mathrm{Ce}^{3+}$ oxidation state with the methyl group of alkyl chains used for the capping ceria NPs. The weak band observed at $805 \mathrm{~cm}^{-1}$ corresponds to $\mathrm{C}-\mathrm{H}$ bending modes. The metal-oxygen $\nu \mathrm{Ce}-\mathrm{O}\left(\right.$ of $\left.\mathrm{CeO}_{2}\right)$ antisymmetric and symmetric stretching vibration peaks ${ }^{19}$ appear as very strong transmissions at 669 and $559 \mathrm{~cm}^{-1}$, respectively.

IR spectra of pure FLC (Fig. 1(b)) gave valuable information about the molecular conformations and fundamental vibration of the functional groups present in FLC. In general, FLCs are the mixtures of two or more organic compounds containing 


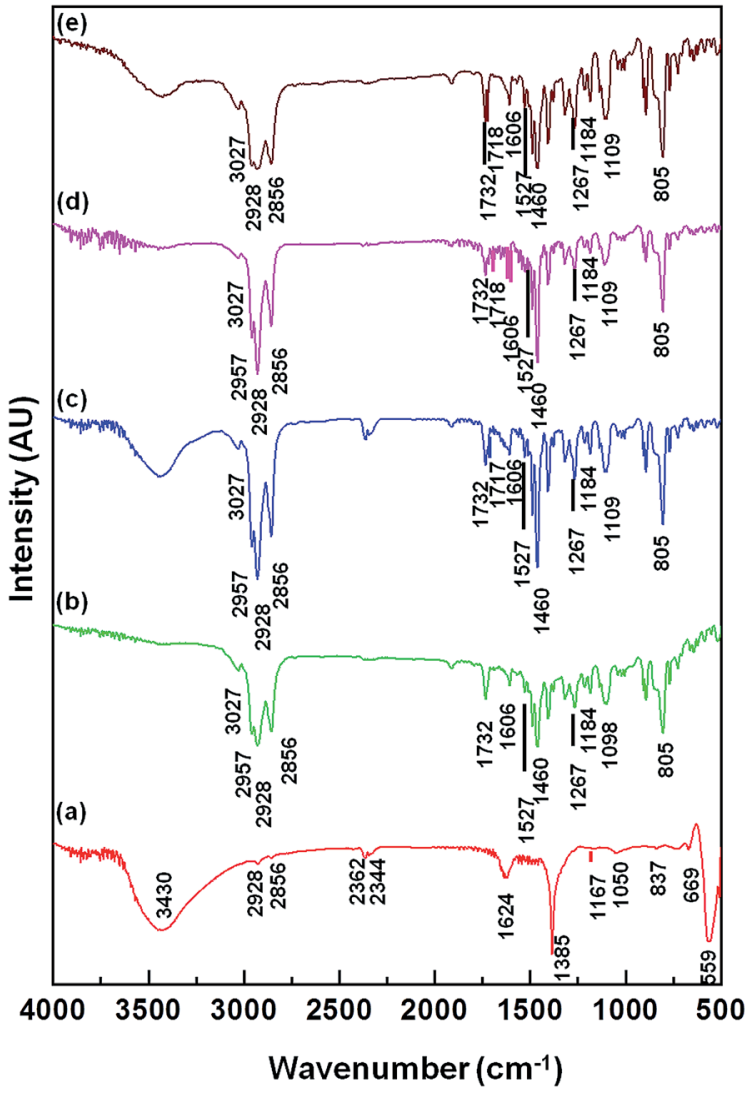

Fig. 1 FTIR spectra of the (a) $\mathrm{CeO}_{2} \mathrm{NPs}$, (b) KCFLC 10s, (c) $1 \mu \mathrm{l}$, (d) $3 \mu \mathrm{l}$ and (e) $5 \mu \mathrm{CeO}_{2}$ NPs dispersed KCFLC 10s.

substituted biphenyl aromatic cores with aliphatic end chains and ester group adjacent to one or more chiral dopant. In this particular FLC, the smectic C host component is made up of difluoroteraphenyls, and the chiral dopant is a cyanohydrin ester, as given below:

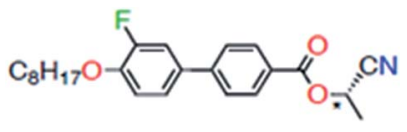

As can be seen from Fig. 1(b), vibrational modes pertaining to the functional groups of FLC substituted biphenyl core group and long alkyl chain with $p$-substitution through oxygen are present. The IR activity of these modes has been attributed to the polarization of all parallel modes averaged over the long molecular axis. However, for $\mathrm{C}=\mathrm{O}$ and $\mathrm{CH}_{2}$ groups, the maximum absorption arise from the polarization over the perpendicular averaged molecular long axis. IR transmission spectrum in Fig. 1(b) shows bands corresponding to $-\mathrm{C} \equiv \mathrm{N}$, $-\mathrm{COO},-\mathrm{CH}_{2},-\mathrm{CH}_{3}$ and $-\mathrm{C}=\mathrm{C}-$ aromatic ring groups. The strong IR peaks observed in Fig. 1(b) are assigned as the fundamental modes arising from FLC cores at 1184, 1267, 1460, 1527, 1606 and $1732 \mathrm{~cm}^{-1}$ and from the alkyl chains at 2856, 2928 and $805 \mathrm{~cm}^{-1} .^{20}$ The three very strong peaks at 2856, 2928 and $805 \mathrm{~cm}^{-1}$ are assigned as the symmetric, antisymmetric stretching and bending modes of $\mathrm{CH}_{2}$, respectively, along the
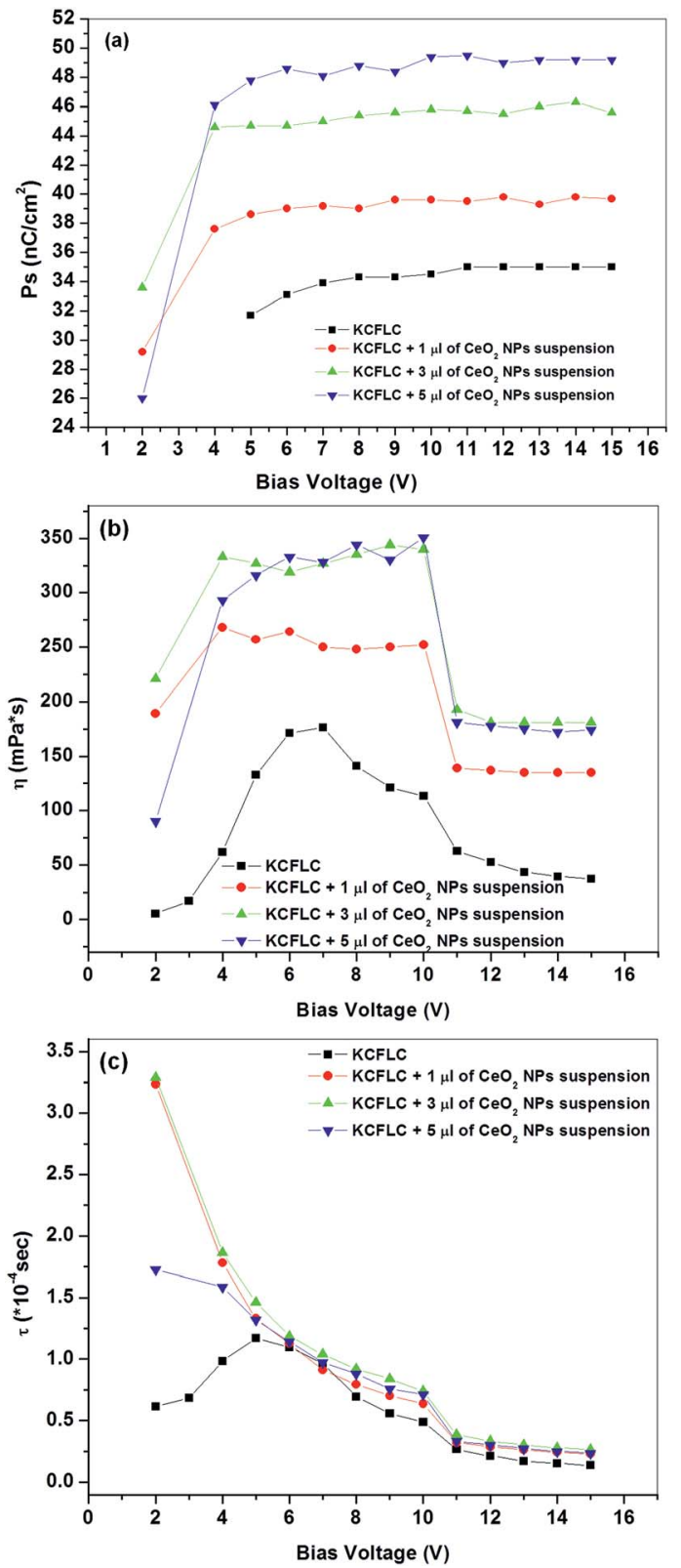

Fig. 2 Behavior of (a) spontaneous polarization $\left(P_{\mathrm{s}}\right),(\mathrm{b})$ rotational viscosity $(\eta)$, and (c) response time $(\tau)$ of pure KCFLC and np- $\mathrm{CeO}_{2}: \mathrm{FLC}$ nanocomposites with applied voltage at $30{ }^{\circ} \mathrm{C}$ temperature.

alkyl chains of the FLC molecules. The peak at $1732 \mathrm{~cm}^{-1}$ is attributed to $\mathrm{C}=\mathrm{O}$ stretching vibration mode of ester carbonyl group and the peaks at 1606 and $1527 \mathrm{~cm}^{-1}$ are obtained due to $\mathrm{C}-\mathrm{C}$ stretching modes of the FLC core. The combination mode of the $\mathrm{C}-\mathrm{C}$ stretch and in-plane wagging vibration of $\mathrm{C}-\mathrm{H}$ of FLC core is observed at $1460 \mathrm{~cm}^{-1}$, while the peaks at 1184 and 1265 $\mathrm{cm}^{-1}$ are associated to the symmetric and antisymmetric stretching vibration of $\mathrm{C}-\mathrm{O}-\mathrm{C}$ group, respectively.

As shown in Fig. 1(c)-(e), the IR transmission spectra of np$\mathrm{CeO}_{2}$ :FLC exhibit the ordering of the IR spectrum with a minor variation in the peak positions of $\mathrm{C}=\mathrm{O}$ (ester carbonyl group) frequencies and a new weak intensity $\mathrm{C}=\mathrm{O}$ bonded chiral group vibrational mode at $1717-1718 \mathrm{~cm}^{-1}$ was observed. In addition 

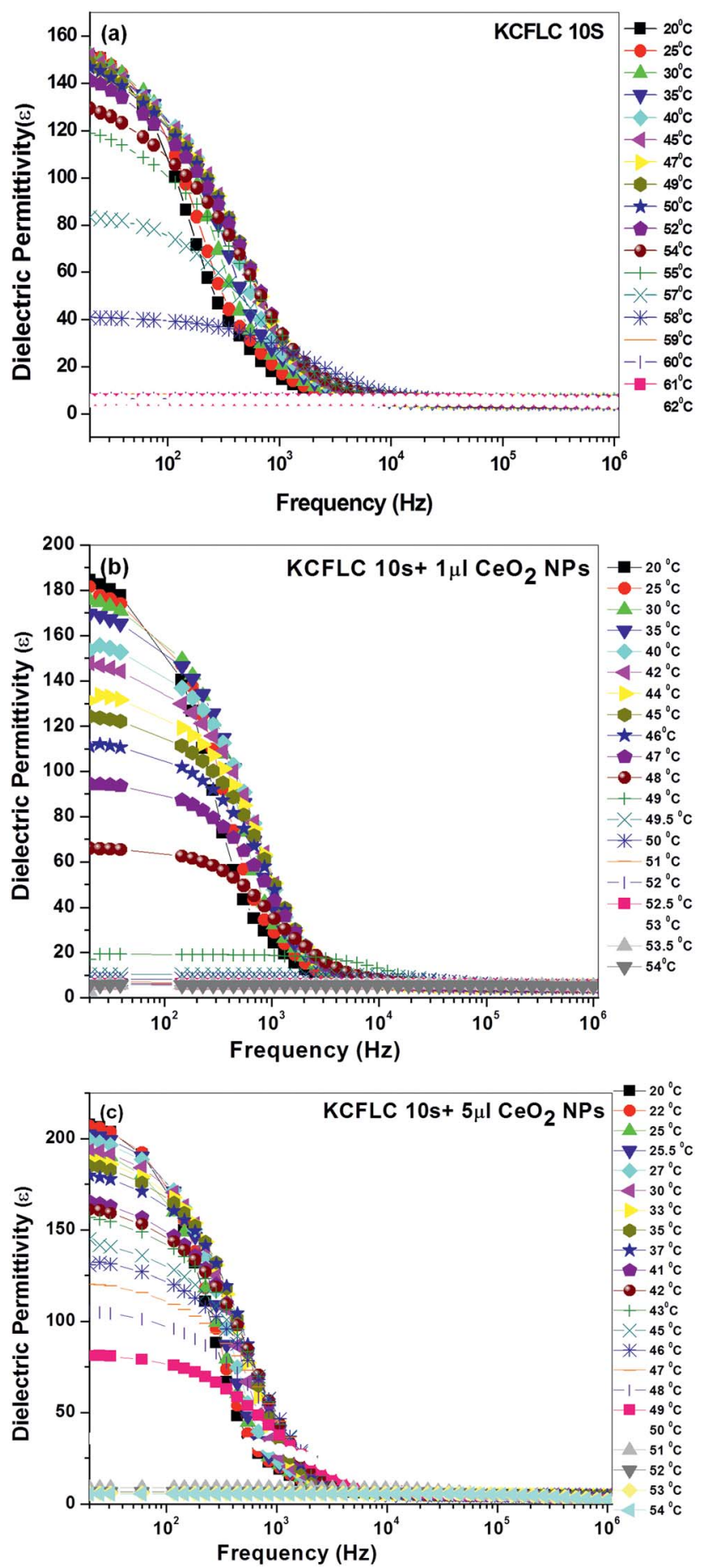

Fig. 3 Frequency variation of dielectric permittivity $\left(\varepsilon^{\prime}\right)$ in (a) FLC, (b) 1 $\mu \mathrm{l}$, and (c) $5 \mu \mathrm{lnp}-\mathrm{CeO}_{2}$ :FLC nanocomposites in SmC*-SmA* phase.

to this, the intensity of $\mathrm{C}-\mathrm{O}$ stretching mode of ester ( $\left.\mathrm{RCOOR}^{\prime}\right)$ transmission peak is shifted from $1098 \mathrm{~cm}^{-1}$ to $1108 \mathrm{~cm}^{-1}$ in $1 \mu \mathrm{l}$ ceria NPs dispersed FLC sample, whereas it shifts to 1109 $\mathrm{cm}^{-1}$ after $3 \mu \mathrm{l}$ and $5 \mu \mathrm{l} \mathrm{CeO} \mathrm{NPs}_{2}$ dispersion. The ester group in FLCs is basically a planar linking group, which entails the lamellar packaging of molecules in a tilted smectic structure. ${ }^{21}$ The easy polarization of $\mathrm{C}=\mathrm{O}$ bond is induced by the

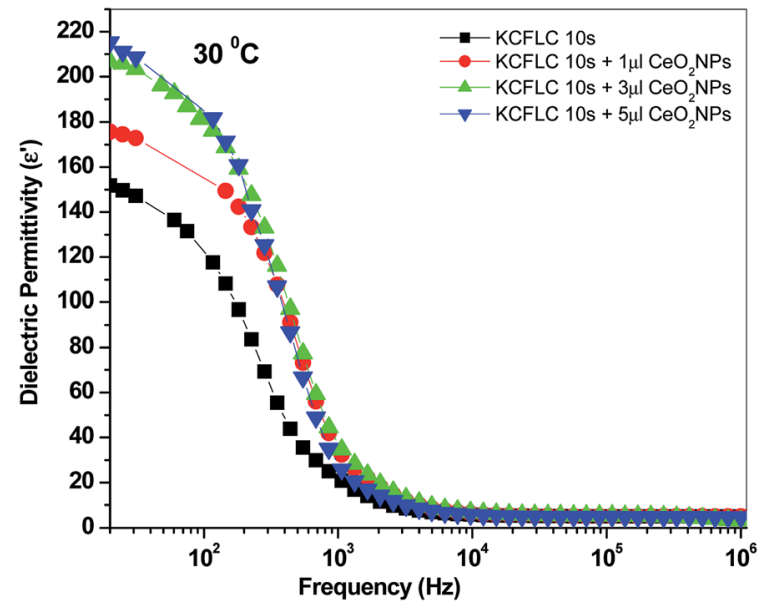

Fig. 4 Frequency variation of dielectric permittivity $\left(\varepsilon^{\prime}\right)$ in $\mathrm{np}-\mathrm{CeO}_{2}$ NPs:FLC nanocomposites at $30{ }^{\circ} \mathrm{C}$ temperature.

delocalization of pi electrons over the ester carbonyl group induced by the adjacent chiral carbon and para bondedbiphenyl aromatic group with the meta bonded strong electron-donating fluorine atom. The shift in frequencies of these bands confirms the stress induced and coordinated bond formation between ester $\mathrm{C}=\mathrm{O}$ and $\mathrm{Ce}^{3+}$ ion through the lone pairs of oxygen by the $\mathrm{CeO}_{2}$ NPs present in the interstitial sites of FLC component containing the planar polar ester group of liquid crystal, which facilitates the easy polarizability of FLC, whereas the alkyl chain bonded part is least affected by the addition of NPs because their peaks do not show a major shift in their positions.

Spontaneous polarization, $P_{\mathrm{s}}$, of FLCs is a very important parameter for their applicability in electro-optic devices because their dynamic properties are governed by a change in the orientation of spontaneous polarization and molecular director on the application of external electric fields. Switching response time, $\tau$, which is another most important physical parameter, is inversely proportional to $P_{\mathrm{s}}\left(\tau \propto 1 / P_{\mathrm{s}} E\right) .{ }^{22}$ Therefore, a higher $P_{\mathrm{s}}$ is desirable for the faster switching of FLC. In order to see the effect of a nano-ceria dispersion on FLC's spontaneous polarization $\left(P_{\mathrm{s}}\right)$, the $P_{\mathrm{s}}$ values were recorded at a temperature of $30^{\circ} \mathrm{C}$ for pure and doped samples at different bias voltages and are demonstrated in Fig. 2(a). Large and consistent increase in saturated $P_{\mathrm{S}}$ values can be noted with increasing amount of nano-ceria concentration. In addition to this, switching takes place at $1.5 \mathrm{~V}$ bias in ceria dispersed samples, whereas in case of pure FLC, $P_{\mathrm{s}}$ could be noted only after applying $4.5 \mathrm{~V}$ bias. This indicates that ceria NPs are facilitating the switching of FLC molecules in external electric field and making it easier to obtain a polarization at a bias as low as $1.5 \mathrm{~V}$. It is well known that the spontaneous polarization in FLC is caused by the electron delocalization over the planar ester functional group bonded to adjacent chiral centre and fluoride bonded biphenyl aromatic core of the nearest neighbouring molecule through wide spread electron cloud. As explained in the previous section, ceria is straining and forming coordination bond with 

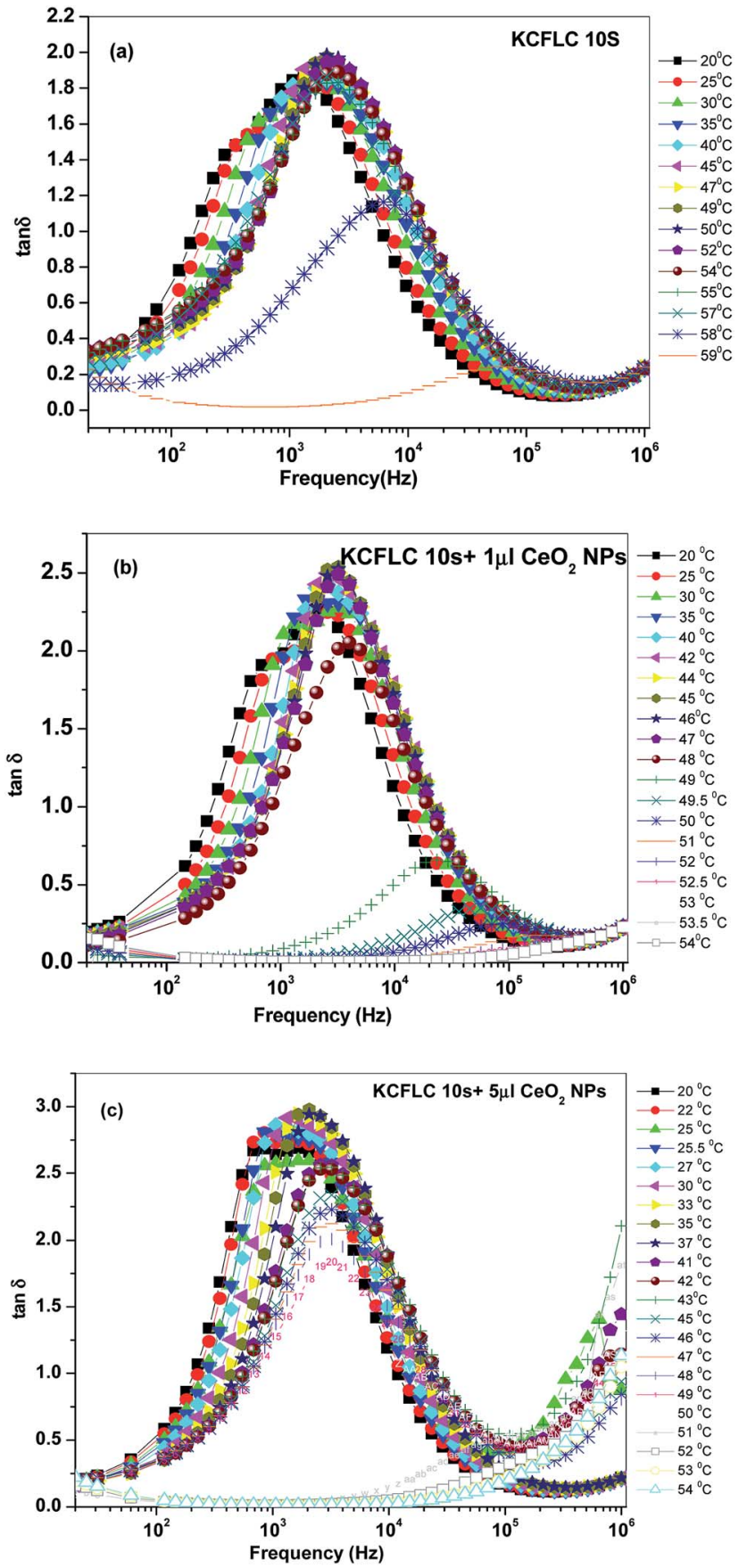

Fig. 5 Frequency variation of dielectric losses $(\tan \delta)$ in SmC*-SmA* phase in (a) FLC, (b) $1 \mu \mathrm{l}$, and (c) $5 \mu \mathrm{lnp}-\mathrm{CeO}_{2}$ : $\mathrm{FLC}$ nanocomposites.

the ester polar component linking group in FLC mixture. This facilitates the easy polarizability of FLC molecules and is believed to be the main cause for the increased value of spontaneous polarization and sensitivity towards the electric field for ceria dispersed sample. The behavior of rotational viscosity $(\eta)$ vs. applied bias voltages recorded at $30{ }^{\circ} \mathrm{C}$ in pure and ceria dispersed FLCs is shown in Fig. 2(b). The bias dependent behavior of viscosity follows the same profile of increase and decrease as that of pure FLC. Because the rotational viscosity coefficient of FLC describes the energy dissipation as a result of

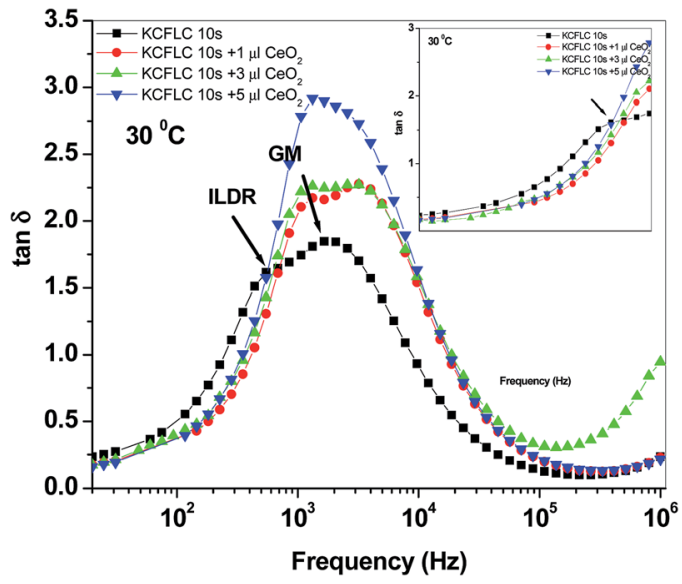

Fig. 6 Freq. vs. $\tan \delta$ profile of $\mathrm{np}-\mathrm{CeO}_{2}: \mathrm{FLC}$ nanocomposites at $30^{\circ} \mathrm{C}$ temperature (ILDR - impurity linked dielectric relaxation; GMGoldstonemode).

the director rotation, the coordinate bond formation between the guest and host molecules lead to steric hindrance with a higher energy loss during the director reorientation process and result into a higher rotational viscosity for all the ceria dispersed analogues. Fig. 2(c) depicts the behavior of response time $v s$. applied bias voltages in pure and $\mathrm{np}-\mathrm{CeO}_{2}: \mathrm{FLC}$ composites. Higher $P_{\mathrm{s}}$ and lower rotational viscosity is desirable for obtaining a faster response time because it is directly proportional to viscosity and inversely proportional to spontaneous polarization through the relation $\tau=\eta / P_{\mathrm{s}} E$. In our ceria dispersed FLC analogues, we observed an increase in both the $P_{\mathrm{s}}$ and $\eta$ after ceria dispersion; however, the ratio of this enhancement (i.e. $\eta / P_{\mathrm{s}}$ ) is such that $\tau$ values do not show an increase beyond a bias of $4.5 \mathrm{~V}$.

To investigate the relaxation processes in the fabricated nanocomposites, temperature and bias dependent dielectric spectroscopy was performed. The frequency variation of the dielectric permittivity for pure FLC and np-CeO ${ }_{2}$ :FLC $(1$ and $5 \mu \mathrm{l}$ concentrations) is given in Fig. 3(a)-(c) in the temperature ranging from deep $\mathrm{SmC}^{*}$ to $\mathrm{Sm} \mathrm{A}^{*}$ phase. As seen in Fig. 3(a), in the undoped sample, the magnitude of $\varepsilon^{\prime}$ is very large in low frequency range $(<1 \mathrm{kHz})$, which is mainly due to the Goldstone mode (phase fluctuations, few $\mathrm{kHz}$ range) contribution to the dielectric permittivity and considered as a usual behavior of FLC materials. ${ }^{8}$ Moreover, it can be seen that as the temperature increases, Goldstone mode (GM) contribution to the permittivity in the $\mathrm{SmC}^{*}$ phase decreases, which leads to very low values of $\varepsilon^{\prime}$ near the $\mathrm{SmC}^{*}-\mathrm{SmA}^{*}$ transition region.

Furthermore, to compare the effect of the addition of $\mathrm{CeO}_{2}$ NPs on the dielectric permittivity $\left(\varepsilon^{\prime}\right)$ values, the profiles of frequency dependent permittivity np-CeO ${ }_{2}$ :FLC nanocomposites are compared at $30{ }^{\circ} \mathrm{C}$ and shown in Fig. 4. After $\mathrm{CeO}_{2}$ NPs addition, $\varepsilon^{\prime}$ increases on increasing the NPs concentration upto $5 \mu \mathrm{l}$, which suggests that the presence of NPs is enhancing the GM contribution to $\varepsilon^{\prime}$.

In order to further elucidate the molecular dynamics in $\mathrm{np}$ $\mathrm{CeO}_{2}$ :FLC systems, the frequency dependent dielectric loss 
factor $(\tan \delta)$ studies were performed. Fig. 5 demonstrates the behavior of frequency $v s$. dielectric loss factor $(\tan \delta)$ at different temperatures for pure and $\mathrm{np}-\mathrm{CeO}_{2}$ :FLC nanocomposites ( 1 and $5 \mu \mathrm{l})$. As can be seen from Fig. 5(a), a low-frequency relaxation mode ( $\sim 268 \mathrm{~Hz}$ ) adjacent to typical GM is observed in the case of pure FLC (KCFLC 10S) material. In general, collective and non-collective molecular processes in FLCs are represented by different dielectric relaxation modes such as Goldstone Mode (GM) and Soft Mode (SM). While GM is associated with the phase fluctuations in the azimuthal orientation of the molecular director, SM is due to fluctuations in the amplitude of the tilt angle. ${ }^{8}$ Additional low frequency relaxation mode, which has also been observed in previous studies conducted on KCFLC 7s and KCFLC 10s compounds, is attributed to the presence of ionic impurities. ${ }^{15}$ It can be noticed from Fig. 5(a) that this low frequency ionic impurity linked dielectric relaxation (ILDR) shifts towards higher frequencies on increasing the temperature and eventually merges with GM at $\sim 46{ }^{\circ} \mathrm{C}$ in pure FLC.

Successively, the effect of Ceria NPs dispersion on the nature of collective, non collective and impurity linked (ILDR) dielectric relaxation could be seen in Fig. 5(b)-(c). Low frequency relaxation peak appeared considerably closer to the GM peak and disappeared at $\sim 36{ }^{\circ} \mathrm{C}$ in ceria dispersed analogues. Furthermore, a comparison of the magnitude and frequency of the relaxation of different modes with varying NPs concentration at $30{ }^{\circ} \mathrm{C}$ is depicted through Fig. 6. The incorporation of ceria NPs leads to an increase in the frequencies of both the relaxation modes. Although the addition of variable concentration of NPs does not affect the frequency of GM, ILDR peak moves towards GM with increasing particle concentration and manifests as a single relaxation peak with np-CeO ${ }_{2}$ :FLC nanocomposites having $5 \mu \mathrm{l}$ concentration. It can also be noted that the GM peak magnitude also increases with the addition of ceria NPs, which yet again indicates the direct coordination of $\mathrm{Ce}^{3+} / \mathrm{Ce}^{4+}$ ions of ceria with FLC molecules that restrict the phase fluctuation mode, leading to a higher absorption of electric field energy. In contrast, losses below the GM mode or on the low frequency wing decreases in the presence of ceria NPs (Fig. 6 inset) and there is the formation of a crossover just on the onset of ILDR mode. The losses in ceria dispersed samples start increasing above the pure FLC's absorption peaks of ILDR and GM mode.

\section{Conclusions}

Investigations on the electro-optical and dielectric properties of ceria NPs dispersed ferroelectric liquid crystal (FLC) have been made and the resulting changes have been understood in the light of structural deformation of the ester functional group, which is a polar linking group adjacent to the FLC chiral center. Dielectric permittivity and $P_{\mathrm{s}}$ showed an enhancement in their values; moreover, polarization switching takes place at a considerably lower bias voltage $(1.5 \mathrm{~V})$ in the presence of ceria NPs. This increase in dielectric permittivity and $P_{\mathrm{s}}$ has been attributed to the FLC lattice straining by the random distribution of $\mathrm{CeO}_{2}$ NPs present in the interstitial sites and structural deformation in the polar component (ester group) by the coordination of $\mathrm{Ce}^{3+}$ ions as inferred from the FTIR transmittance spectra of FLC-ceria sample. The shift in the peak position of $\mathrm{C}=\mathrm{O}$ and $\mathrm{C}-\mathrm{O}$ stretching modes of ester $\left(\mathrm{RCOOR}^{\prime}\right)$ and an appearance of a new weak intensity peak of $\mathrm{C}=\mathrm{O}$ bonded to FLC adjacent chiral group at $1718 \mathrm{~cm}^{-1}$ confirmed the stress induced by the substitution of $\mathrm{CeO}_{2} \mathrm{NPs}$ in the interstitial sites of FLC matrix and coordinate bond formation by the lone pairs of the carbonyl oxygen with $\mathrm{Ce}^{4+}$ ions. Such type of linkages encourages the easy polarizability of FLC molecules. In addition, the loss profile ( $\tan \delta v s$. Freq) exhibits an impurity related relaxation mode on the lower frequency side of $\mathrm{GM}$ in the $\mathrm{Sm} \mathrm{C} \mathrm{C}^{*}$ phase of the pure FLC material (KCFLC 10S), which shift towards high frequency side in FLC-ceria NPs nanocomposites and manifests as a single relaxation peak at 5 $\mu \mathrm{l}$ concentration.

\section{Acknowledgements}

The authors sincerely thank the Director, IARI and Head, Agricultural Chemicals Division, IARI for continuous encouragement and interest in this study. Authors also wish to thank Sh. K. K. Somayajulu and Dr Suresh for FTIR characterizations. One of the authors (P. Goel) is also thankful to DST, New Delhi, for financial support under INSPIRE Faculty Scheme (IFA12-PH-38).

\section{References}

1 P. G. De Gennes and J. Prost, The Physics of Liquid Crystals, Oxford Science Publications, Clarendon, Oxford, 1995.

2 N. A. Clark and S. T. Lagerwall, Appl. Phys. Lett., 1980, 36, 899.

3 I. Dierking, Polym. Chem., 2010, 1, 1153.

4 P. J. Collings, Liquid Crystals: Nature's Delicate Phase of Matter, Princeton University Press, Princeton, 1990.

5 R. B. Meyer, L. Liebert, L. Strzelecki and P. Keller, J. Phys., Lett., 1975, 36, 69.

6 W. Haase and S. Wrobel, Relaxation Phenomena: Liquid Crystals, Magnetic Systems, Polymers, High-Tc Superconductors, Metallic Glasses, Springer, Heidelberg, Germany, 2003.

7 C. Weder, C. Sarwa, A. Montali, C. Bastiaansen and P. Smith, Science, 1998, 279, 835.

8 P. Goel, G. Singh, R. P. Pant and A. M. Biradar, Liq. Cryst., 2012, 39(8), 927.

9 P. Goel, P. L. Upadhyay and A. M. Biradar, Liq. Cryst., 2013, $40(1), 45$.

10 A. K. Srivastava, A. K. Misra, J. P. Shukla and R. Manohar, Phys. Lett. A, 2008, 372(41), 6254.

11 A. F. Shevchuk, D. A. Naiko, A. V. Koval'chuk and E. V. Basiuk (Golovataya-Dzhymbeeva), Ukr. J. Phys., 2004, 49(12A), A21.

12 P. Malik, A. Chaudhary, R. Mehra and K. K. Raina, Adv. Condens. Matter Phys., 2012, 853160.

13 J. S. Roy, T. P. Majumder and R. Dabrowski, J. Lumin., 2014, 148, 330.

14 P. Goel, M. Arora and A. M. Biradar, RSC Adv., 2014, 4, 11351. 15 T. Joshi, J. Prakash, A. Kumar, J. Gangwar, A. K. Srivastava, S. Singh and A. M. Biradar, J. Phys. D: Appl. Phys., 2011, 44, 315404 . 
16 K. Schwarz, Proc. Natl. Acad. Sci. U. S. A., 2006, 103, 3497. 17 N. Shehata, K. Meehan, M. Hudait and N. Jain, J. Nanopart. Res., 2012, 14, 1173.

18 N. V. Skorodumova, R. Ahuja, S. I. Simak, I. A. Abrikosov, B. Johansson and B. I. Lundqvist, Phys. Rev. B: Condens. Matter Mater. Phys., 2001, 64, 115108.
19 A. A. Athawale, M. S. Bapat and P. A. Desai, J. Alloys Compd., 2009, 484, 211.

20 J. G. Zhao, T. Yoshihara, H. W. Siesler and Y. Ozaki, Phys. Rev. E: Stat., Nonlinear, Soft Matter Phys., 2001, 64, 031704.

21 P. J. Collings and M. Hird, Introduction to Liquid Crystals: Chemistry and Physics, Taylor and Francis, 1998.

22 P. Goel and A. M. Biradar, Appl. Phys. Lett., 2012, 101, 074109. 